\title{
EDUCAÇÃO SUPERIOR EM TEMPOS DE CRISE: HÁ ESPAÇO NAS POLÍTICAS DE EDUCAÇÁO PARA A DISCUSSÁO DO PROFESSOR UNIVERSITÁRIO?
}

\author{
Higher education In TIME OF CRISIS: IS THERE SPACE \\ IN THE EDUCATION POLICIES FOR THE DISCUSSION OF THE \\ UNIVERSITY TEACHER?
}

\author{
Silvia Regina Canan \\ Doutora em Educação pela UNISINOS. \\ Professora do Programa de Pós-Graduação em Educação da Universidade Regional \\ Integrada do Alto Uruguai e das Missóes, Frederico Westphalen, RS- Brasil \\ ORCID: https://orcid.org/0000-0003-4504-3680 \\ silvia@uri.edu.br
}

Camila de Fátima Soares dos Santos Mestre em Educação pela Universidade Regional Integrada do Alto Uruguai e das Missōes. Professora da Universidade Federal da Fronteira Sul, Chapecó, SC - Brasil ORCID: https://orcid.org/0000-0003-0644-8570 camilafss13@gmail.com

\begin{abstract}
Resumo: O presente artigo objetiva refletir sobre o contexto da educaçáo superior em tempos de crise nesta segunda metade do século XXI, considerando a profissionalizaçáo do docente. Esse debate é fruto de uma pesquisa bibliográfica que tem base em estudos teóricos desenvolvidos no Núcleo de Estudos em Políticas e Processos de Educaçáo Superior (NEPPES) do Programa de Pós-Graduação em Educação da URI/FW, vinculado a linha de Pesquisa do PPGEDU: Políticas Públicas e Gestão da Educação, tomando em consideração pesquisas já desenvolvidas pelo Núcleo e referenciais bibliográficos de autores que estudam a temática em âmbito nacional e internacional. $\mathrm{O}$ mote dos estudos gira em torno do fato de que o professor da educaçáo superior, além de uma formação específica que o habilite ao magistério de uma determinada disciplina ou área do conhecimento, também necessita ter domínio da competência pedagógico-didática e da dimensão político-educacional na qual está inserido. A análise dos referenciais pesquisados oportunizou refletir sobre a profissionalização docente na Educação Superior, particularmente quanto à necessidade de tornar mais significativo o processo de aprendizagem dos educandos, futuros profissionais, a partir da prática docente. Para a discussão da temática, utilizamos as categorias: formação docente, profissionalidade docente e processo educativo.
\end{abstract}

Palavras-chave: Educação Superior. Formação de Professores. Prática Docente na Educação Superior. Processos Educativos. Profissionalização Docente. 
Aвstract: This article aims to reflect on the context of higher education in times of crisis in the second half of the 21st century, considering the professionalization of the teacher. This debate is the result of a bibliographical research that is based on theoretical studies developed in the Nucleus of Studies on Policies and Processes of Higher Education (NEPPES) of the Post-Graduation Program in Education of the URI/FW, linked to the PPGEDU research line: Public Policies and Education Management, taking into account researches already developed by the Nucleus, and bibliographic references of authors who study the theme in national and international scope. Our research problem revolves around the fact that the higher education teacher must have a specific training that enables him/her to a certain discipline or area of knowledge, but also needs to have mastery of pedagogical-didactic competence, and the educational-policy dimension, in which is inserted. The analysis of the references researched gave opportunity to reflect on the teacher professionalization in Higher Education, in order to make more meaningful the learning process of learners, future professionals, from of teaching practice. For the discussion of the theme, we use the categories: teacher training, teacher professionalism and educational process.

Keywords: Educational Processes. Higher Education. Teaching Practice in Higher Education. Teacher Professionalism. Teacher training.

\section{Introduçáo}

Dentre as tantas questóes que se impóem neste momento da história da educação brasileira, geradora de intensos debates no âmbito acadêmico, encontramos aquela que diz respeito à formação docente para a atuação na Educação Superior, tendo o campo das políticas públicas como dos mais abertos para estudos e considerando, no caso do Brasil, que a legislação educacional é omissa quanto à necessidade de formação de matiz pedagógico-didático.

Nessa perspectiva, ao trazermos essa questão novamente à pauta de debates, o fazemos na condiçáo de quem estuda a temática e tem uma preocupação com a valorização e qualificação do ensino como um dos importantes pilares da universidade, sem, evidentemente, desqualificar a pesquisa e a extensão (e, recentemente, a internacionalização ${ }^{1}$ ). Somente para relembrar, a menção que a $\mathrm{LDB} / 96$ faz sobre a formação do docente universitário, em seus artigos 65 e 66, a remete à pós-graduaçáo, com prioridade para os programas stricto sensu (mestrados e doutorados), ressalvando que a obrigatoriedade de 300 horas de estágio refere-se somente à formação dos professores que atuarão na Educação Básica. Ao deixar esse campo em aberto, as políticas públicas concordam que a experiência e o 
conhecimento na área específica de formação se sobressaem a qualquer outra possibilidade formativa.

O presente artigo objetiva apresentar reflexóes sobre o contexto da profissionalização do docente universitário, a partir de estudos teóricos desenvolvidos no Núcleo de Estudos em Políticas e Processos de Educação Superior (NEPPES) do Programa de Pós-Graduação em Educação da URI/FW, vinculado a linha de Pesquisa do PPGEDU: Políticas Públicas e Gestão da Educaçáo. Partimos do pressuposto de que o professor da Educação Superior precisa ser portador de uma formação específica que o habilite a determinada disciplina ou área do conhecimento, mas, para além disso, necessita dominar competências pedagógico-didáticas e atentar para a dimensão política da educação, enquanto profissional inserido em um contexto social específico e essencialmente contraditório.

Para tanto, trazemos para a discussão autores que pesquisam a formação para a docência na universidade, enfatizando uma profissionalização docente que torne mais significativo o processo de aprendizagem dos alunos a partir da prática, desse modo melhorando desempenho da profissão.

Estudos como de Leite e Ramos (2010) nos mostram que a universidade precisa rever sua condição de instituição inabalável para ser uma instituição que faz parte do sistema educativo e, por isso, incorpora as mudanças e novas proposiçôes que vão ocorrendo nesse sistema. Isso implica o reconhecimento de que a docência, em sua forma tradicional, não dá mais conta de desenvolver a aprendizagem, a autonomia e as competências necessárias ao futuro profissional para que possa exercer sua profissão.

Essas reflexôes colocam a universidade, definitivamente, diante de um novo paradigma em que a docência como reprodução de práticas exitosas, por si só, já não atende mais às exigências no campo da formação do acadêmico que vem até ela em busca de novos e diferenciados conhecimentos. Nessa matriz não podemos negar as questôes tecnológicas, que se colocam, por exemplo, pela via do ensino hibrido, o qual propõe a integração entre o ensino presencial e aulas on line, despontando como alternativa às tradicionais aulas em que o professor faz longos discursos e cobra suas explicaçóes em provas. Sobre essa questão Cerutti e Nogaro (2017, p. 1600), esclarecem: 
Neste contexto, aulas passam por outra configuração imprimindo mais dinâmica, possibilitam ao educando buscar materiais que ampliem seu conhecimento e que tragam novas indagaçôes, que façam com que o aluno queira buscar cada vez mais novos conhecimentos, participe do que Lévy (1999) denomina cibercultura. Esta é uma nova forma de comunicação gerada pela interconexão de computadores ao redor do mundo, abrangendo um universo informacional que abriga os seres humanos que a utilizam.

Contrastando com essas questôes atuais e instigantes, convivemos com as bases do modelo Luniversitário francês (napoleônico) que inspirou a educação superior no Brasil com a herança de uma supervalorização das Ciências Exatas e Tecnológicas em detrimento das Ciências Humanas. Dessa forma, a Educação Superior voltou-se, desde seu início, à formação de profissionais, com maior destaque para determinadas profissóes. Esse modelo também inseria a ideia de que o professor estava acima de seus alunos como detentor de conhecimentos e práticas, que esses precisavam aprender para receber seus diplomas e exercer a profissão a que aspiravam, numa atitude que denotava um autoritarismo exacerbado, já que o professor ensinava a um aluno que deveria aprender.

\section{Formação para a docência universitária: como ler essa questáo?}

No campo da formação de professores, o qual envolve diferentes ideologias, concepções, práticas e políticas educacionais, a docência universitária merece um olhar especial, podendo ser pensada e contextualizada num processo contínuo e permanente, cujo desenvolvimento é processual e, como tal, contínuo. Nesse sentido, "A formação não é um constructo arbitrário, pois sua proposta decorre de uma concepção de educação e do trabalho que cabe ao docente realizar." (CUNHA, 2008, p. 9). Assim, a docência universitária caracteriza-se como atividade plural e complexa que vai muito além do mero ensino em sala de aula. 
Se considerarmos que a formação docente não é neutra nem envolve apenas aspectos estritamente técnicos, e que é uma ação intencional que exige posicionamento e tomada de decisóes, ela não pode ser confundida com outros conceitos como educação, ensino, treino, etc., pois envolve, necessariamente, uma dimensão pessoal de desenvolvimento humano global, podendo ser entendida como:

[...] a área de conhecimentos, investigação e de propostas teóricas e práticas que, no âmbito da didática e da organização escolar, estuda os processos através dos quais os professores - em formação ou em exercício - se implicam individualmente ou em equipe, em experiências de aprendizagem através das quais adquirem ou melhoram os seus conhecimentos, competências e disposiçôes, que lhes permitem intervir profissionalmente no desenvolvimento do seu ensino, do currículo e da escola, com o objetivo de melhorar a qualidade da educação que os alunos recebem. (GARCIA, 1999, p. 26)

Ampliar conhecimentos, revisar práticas, repensar metodologias e processos avaliativos implica investir sempre na qualificação profissional dos educadores e educadoras, pois eles têm uma tarefa complexa a desenvolver uma vez que "as instituiçôes de Ensino Superior, como instituiçóes educativas, são parcialmente responsáveis pela formação de seus membros como cidadãos (seres humanos e sociais) e profissionais competentes." (MASETTO, 1998, p. 13). Entende-se, portanto, que se espera do docente a capacidade de educar para a cidadania, para o mundo do trabalho, para a vida, proporcionando ao estudante a formação científica necessária ao desenvolvimento profissional e pessoal. Esse conjunto está ligado de forma umbilical à qualidade da formação dos professores, a qual passa a definir novas exigências aos profissionais docentes.

Foi apenas recentemente que a docência universitária passou a ser compreendida como profissão que exige capacitação específica, considerando a necessidade de outros tipos de conhecimentos, os pedagógicodidáticos, por exemplo, os quais são distintos da formação científica e técnica, apreendidos para atuação em outros espaços profissionais que não a docência, portanto, a docência, exige, além dos saberes específicos de 
determinada área do conhecimento, um outro conjunto de saberes que estão diretamente implicados no fazer cotidiano do professor.

As exigências para ser professor universitário eram apenas, até há pouco tempo, a de dominar os conteúdos específicos da área de atuação em que o professor se forma para exercer sua carreira profissional (que não era, necessariamente, a docência), e não as metodologias e práticas pedagógicas. A atividade docente centrava-se no processo de ensino, o que, náo raras vezes, resultava numa aprendizagem mecânica. $O$ processo centrado no ensino ainda hoje possui um forte viés nas universidades, apresentando-se, em muitas situações, como um problema, já que a nova geração tem uma relação muito estreita com as tecnologias e um acesso ilimitado a informaçóes, diferentemente de tempos passados.

Em muitas Instituições de Educação Superior, não se discute o fato de que o trabalho docente inclui um olhar não dogmático, que cabe ampliar no sentido de minimizar a bipolaridade teoria e prática, ensino e aprendizagem. Não há processo que se configure sem considerar as duas perspectivas, uma vez que os dois polos, no caso da educação, não se opóem. O fazer pedagógico-didático pressupóe que o (a) professor (a) possa desenvolver, ao longo de sua formação, determinadas habilidades que lhe ajudarão no processo de construção do conhecimento com seus alunos.

A tarefa docente, hoje, é considerada uma ação complexa, que se desenvolve em um contexto desafiador, o que faz com que as exigências em torno da prática pedagógica ultrapassem o modelo transmissivo que simplifica o ensino, condensado, muitas vezes, tão somente, nos conhecimentos específicos de uma disciplina e em sua memorização. A tarefa docente pressupóe trabalhar os conteúdos numa relaçáo direta e dinâmica com a formação para a vida, para o trabalho e para a cidadania, ou seja, em uma perspectiva que permita transformar em conhecimento as informaçôes recebidas através das tecnologias da informação e da comunicação, das aulas, dos encontros, das pesquisas, dando vida e sentido a essas aprendizagens.

Esse modo de entender a docência universitária, constitui desafio permanente para educadores e educandos, uma vez que ainda se verifica, na universidade, uma grande resistência em relaçáo às práticas que buscam superar o ensino de modelo tradicional ou tecnicista. Por essa via, Cunha (2005, p.70) nos lembra: "Se a concepção de formação não é neutra, como 
toda a característica do ato humano, é preciso analisá-la numa perspectiva que se afaste da concepção meramente técnica." E avança lembrando que a profissão de professor universitário moveu-se, historicamente, tomando por base a profissão que se exercia paralelamente à docência, assim,

A ideia de quem sabe fazer, sabe ensinar, deu sustentação à lógica do recrutamento dos docentes. Além disso, a universidade, pela sua condição de legitimadora do conhecimento profissional, tornou-se tributária de um poder que tinha raízes nas macroestruturas sociais do campo do trabalho, dominadas, fundamentalmente, pelas corporações. (id. ibid) (CUNHA, 2005, p. 70)

Essa foi a lógica inicial que caracterizou a formação dos professores universitários. Cabe também destacar que esse modelo de formação influenciado pela ciência moderna ${ }^{2}$ priorizou o conhecimento socialmente legitimado, com ênfase no conteúdo específico em detrimento do conhecimento pedagógico e das humanidades. É importante compreender que a formação profissional do professor está relacionada, ainda, ao contexto social, econômico e cultural, como nos diz Cunha (2010, p. 32):

A formação profissional do professor implica concebê-lo como ator/autor da sua trajetória de vida e emergente da teia econômica, social e cultural em que está inserido e como profissional que busca a formação, reconhece suas necessidades e as do contexto em que atua, se compromete reflexivamente na transformação das práticas e na afirmação da profissionalidade docente. A formação desse profissional precisa garantir articulação entre teoria e prática, levando em conta a reflexão epistemológica da prática.

Estrutura e organização da Educação Superior no Brasil, portanto, têm enfatizado e privilegiado o domínio de conhecimentos específicos e experiências profissionais como únicos requisitos para a docência nos cursos superiores. Constata-se, por isso, uma lacuna no fazer docente no que se refere às metodologias e à didática das aulas. Tratar da formação 
de docentes universitários, nesse contexto, impóe descortinar um amplo e complexo cenário que se apresenta na Educação Superior.

O conteúdo pedagógico da formação e do fazer docente universitários não ganha destaque uma vez que o modelo em evidência é a formação com ênfase na pesquisa em áreas específicas, proposta que se materializa em programas stricto sensu. Nesse contexto, há uma visão reduzida desse processo, direcionada, especialmente, ao saber científico. Cunha (2000) aponta que tais saberes são de grande valia, mas é preciso analisá-los de forma crítica. $\mathrm{Na}$ ocupação do magistério, a aprendizagem do ofício de professor exige um processo longo de estudos e a apropriaçáo de conhecimentos teórico-práticos voltados para a área de atuação.

A formação do professor ocorre de forma permanente, como nos diz Freire (1991, p. 34), dado que "ninguém começa a ser professor numa certa terça-feira às 4 horas da tarde... Ninguém nasce professor ou é marcado para ser professor. A gente se forma como educador permanentemente na prática e na reflexão sobre a prática.” Por isso, quando programas de pós-graduação, e mesmo de graduação, consideram apenas a formação científica na área específica do profissional, não é possível ter uma visão global e abrangente dos processos de ensinar e aprender e de viver em sociedade.

Pensar a docência é refletir sobre a teoria e a prática do professor, seu planejamento, sua metodologia, sua fundamentação teórica, sua formação continuada. Docência tem origem na palavra latina docere, que significa ensinar, e sua ação se complementa, necessariamente, com discere, que significa aprender. Isso significa entender a docência como o exercício do magistério voltado para o processo que implica ensino e aprendizagem, evitando a polarização, ainda que seja importante que a docência vislumbre o processo de aprendizagem dos alunos, pois isso muda o entendimento do que seja a práxis pedagógica. Masetto (2003, p. 37) contribui para esse debate nos seguintes termos:

Ao falarmos de processo de aprendizagem, queremos nos referir a um processo de crescimento e desenvolvimento de uma pessoa em sua totalidade, abarcando minimamente quatro grandes áreas: a do conhecimento, a do afetivo-emocional, a de habilidades e a de atitudes ou valores. 
Aprender, portanto, ultrapassa as fronteiras da memorização, da reprodução; é muito mais que adquirir determinado conhecimento científico. Aprendizagem requer o desenvolvimento da pessoa enquanto ser humano e cidadão, pensado em sua totalidade orgânica e abarcando os valores que o tornarão um profissional competente e ético. $\mathrm{O}$ exercício da docência universitária torna-se, assim, uma atividade de imensa responsabilidade e complexidade e que não se restringe à sala de aula, mas perpassa os muros da universidade, vai além, pois pressupóe um conjunto de atividades "[...] pré, inter e pós-ativas que os professores têm de realizar para assegurar a aprendizagem dos alunos." (GARCIA, 1999, p. 243). Tal complexidade se explica pelo fato de seu exercício estar dirigido a garantir a aprendizagem do estudante, e não à mera transmissão de conteúdo, envolvendo condiçóes singulares e exigindo uma multiplicidade de saberes, competências e atitudes que precisam ser apropriados e compreendidos em suas relaçóes.

Apesar de bastante difundida a crença de que o domínio dos conhecimentos específicos do campo científico, ou profissional, assegura a transposição para uma efetiva aprendizagem do estudante, a ausência de saberes pedagógico-didáticos limita a ação do docente e causa distorçôes de natureza variada no processo de ensinar e aprender. A complexidade da docência universitária se explica, também, por seu caráter interativo, pois, como argumenta Tardif (2002), ensinar é desenvolver um programa de interaçôes com os estudantes, com vistas a determinados objetivos formativos que envolvem a aprendizagem de conhecimentos, mas também de valores, atitudes, formas de ser e de se relacionar.

O fazer docente pressupôe um processo complexo de negociações, expectativas, interesses, necessidades entre os atores envolvidos. Esse caráter interativo configura a docência "[...] como uma prática social complexa carregada de conflitos de valor e que exige posturas éticas e políticas." (PIMENTA; ANASTASIOU, 2002, p. 14) A universidade precisa estar sempre atenta a essas questôes e colocar-se na condição de instituição que desempenha a função de formar e, para tanto, necessita compreender e interagir com o contexto social, político e cultural em que está inserida. Essa a forma de promover uma formação altamente qualificada para os estudantes, tanto no campo profissional quanto no campo pessoal (que implica sua ação como cidadão) - eis seu compromisso ético-político.Sendo 
a universidade um espaço de conexão de conhecimentos, subjetividades e culturas, dela são exigidos conteúdos científicos, tecnológicos e artístico/culturais altamente especializados, orientado para a formação de uma profissão (LUCARELLI, 2004). Formação essa que, no dizer de Tardif (2002), deve ser voltada para a reflexão, o discernimento e a compreensão de situaçóes problemáticas do contexto da prática profissional; para a definição de objetivos pertinentes à situação; para a identificação dos meios adequados para atingi-los. Isso implica, para o docente universitário, a tarefa de compreender criticamente a profissão em foco e o contexto mais amplo no qual ela se insere. Ser docente, nesse cenário, representa um grande desafio, o qual exige uma formação que contemple as aquisiçôes mínimas necessárias para desempenhar com êxito suas funções, para que a docência não seja exercida de forma improvisada. (FÁVERO, 2013)

A atividade docente, na Educação Superior, tem sido exercida por profissionais das mais diferentes áreas do conhecimento. Para muitos entre eles, dar aulas na universidade se caracteriza como uma forma de emprego temporário para ingressar de modo imediato no mercado de trabalho. Nesse caso, parte considerável desses profissionais não faz da docência um objeto de estudo, reflexão, problematização ou pesquisa (id.ib.). (FÁVERO, 2013). A docência vai acontecendo sem uma preparação específica com a prática em sala de aula, o que, por vezes, dificulta o processo de ensino e aprendizagem.

Cabe destacar que, nos últimos anos, a expansão das universidades também foi expressiva, gerando aumento no número de profissionais que passaram a exercer a função docente no cenário da Educação Superior. Essa realidade vem acompanhada de incertezas e preocupaçóes como o temor em relação ao ensino de baixa qualidade, que póe em risco a formação dos futuros profissionais; receio de uma formação superficial dos docentes, que assumem como titulares de disciplinas sem a devida preparação; carência de conhecimentos teóricos mais aprofundados; descrença em metodologias que possam contribuir com aulas mais prazerosas e que resultem em conhecimentos significativos para os alunos; grande experiência como acadêmico da graduação e pós-graduação stricto sensu e nenhuma experiência docente, o que faz com que muitos professores reproduzam o modo de 'dar aulas' de seus orientadores, confundindo trabalho com pesquisa e trabalho com ensino. 
Diante da importância que entendemos deva ter formação docente para quem atua ou quer atuar na educação superior, defendemos que esse preparo deva se fazer acompanhar de profundo conhecimento da área de formação específica do campo de atuação e de conhecimentos pedagógico-didáticos, os quais se tornam essenciais para uma prática docente qualificada, atualizada e inovadora no contexto universitário atual, destacando a construção do conhecimento numa perspectiva dialética e crítica de educação. Nessa linha, Pimenta (2012, p. 30) nos ensina: "Os saberes pedagógicos podem colaborar com a prática. Sobretudo, se forem mobilizados a partir dos problemas que a prática coloca, entendendo, pois a dependência da teoria em relação à prática [...]" Daí a necessidade premente de desenvolver saberes teóricos e práticos, num processo permanente que promova a profissionalidade docente.

\section{Profissionalidade docente e saber pedagógico-didático: como avançar?}

A profissionalidade pode ser traduzida como o movimento da profissão, a formação docente na busca de um desenvolvimento profissional e pessoal. Sacristán (1993, p. 54) fala da profissionalidade "como a expressão da especificidade da atuação dos professores na prática, isto é, o conjunto de atuaçôes, destrezas, conhecimentos, atitudes e valores ligados a elas que constituem o específico de ser professor." Nessa perspectiva, possivelmente,

para o caso do trabalho docente, a concepção de profissionalidade seja mais adequada do que a de profissão. Isto porque o exercício da docência nunca é estático e permanente; é sempre processo, é mudança, é movimento, é arte; são novas caras, novas experiências, novo contexto, novo tempo, novo lugar, novas informações, novos sentimentos, novas interações. (SACRISTÁN, 1993, p. 54).

A docência universitária e a profissionalidade, que no contexto universitário conta com público e cursos diversos em que um professor 
muitas vezes atua em mais de um curso e em mais de uma instituição, pode ser discutida à luz da necessidade de entendermos a atividade ou ação docente de forma diferenciada da que historicamente se desenvolveu na universidade. Tal concepção comunga com a ideia de que a formação e a profissionalização docente têm como objetivo a potencialização da aprendizagem do educando, entendendo-se a profissionalização como um processo por meio do qual os educadores também podem melhorar seu estatuto, elevar seus rendimentos e aumentar o seu poder de autonomia (NÓVOA, 1992). A profissionalidade docente, segundo Masetto (2002, p. 20), exige o domínio de, no mínimo, quatro grandes eixos: “o próprio conceito de processo de ensino-aprendizagem, o professor como conceptor e gestor do currículo, a compreensão da relação professor-aluno e aluno-aluno no processo, e a teoria e a prática básicas da tecnologia educacional." No olhar do autor, percebe-se que a exigência ao docente vai desde o domínio de práticas específicas até a compreensão de relaçôes subjetivas do dia a dia.

$\mathrm{Na}$ mesma linha, estudos desenvolvidos em universidades ${ }^{3}$, tomando como base seus programas de pedagogia universitária, nos mostram que a preocupação com o ensino nos cursos de graduação e com o despreparo dos professores para o desenvolvimento dessa atividade na Educação Superior é uma realidade a ser enfrentada por todas as universidades. Almeida e Pimenta (2011, p.23) nos alertam que "O ensino na universidade, por sua vez, constitui um processo de busca e construçáo científica e de crítica ao conhecimento produzido, ou seja, de seu papel na construção da sociedade." Nesse sentido, alertam também as autoras, partindo de estudos de Pimenta e Anastasiou (2002), que o ensino é marcado por algumas características que lhe são próprias e que envolvem: dominar conhecimentos, métodos e técnicas científicos; propor a interdisciplinaridade uma possibilidade de superar a fragmentação da formação; desenvolver a capacidade de reflexão com vistas à autonomia dos alunos; considerar que ensinar pode estar integrado a pesquisar; desenvolver habilidades de pesquisa que integrem os cursos e evitem o isolamento de alunos e professores em laboratórios; substituir o ensino que se limita a transmitir conteúdos por um ensino que integre investigação, análise e compreensão epistemológica, dentre outras. 
Por essas características fica evidente o quanto o ensino na graduaçáo é uma atividade complexa que demanda formação profissional adequada que permita uma prática docente diferente da que vem sendo desenvolvida por uma grande parcela dos professores há tanto tempo na universidade. Isso exigirá que repensemos a cultura acadêmica e o modo como são conduzidas as aulas. Muito mais do que retórica, o professor terá que se reinventar, estimulando a pesquisa e a discussão dos temas investigados, com estudos de caso, utilização da tecnologia digital, trocas de experiência entre turmas e colegas do mesmo curso e de outros, enfim, haverá que se ter um novo olhar sobre o compromisso e o comprometimento profissional de quem forma profissionais, de todas as áreas, para a Educação Superior. Nessa linha, Almeida e Pimenta (2011, p.26) esclarecem: "O conjunto de açôes que caracteriza a docência universitária pressupóe elementos de várias naturezas, o que coloca aos sujeitos por ela responsáveis um rol de demandas, contribuindo para configurá-la como um campo complexo de ação."

Esse campo de açóes de grande complexidade exige a formação docente sob dimensóes diversas, entre elas a profissional, a pessoal e a organizacional. Dimensóes essas que podem ser assim entendidas:

[...] a dimensão profissional, onde se aninham os elementos definidores da atuação, como a incessante construção da identidade profissional, as bases da formação (inicial ou contínua), as exigências profissionais a serem cumpridas; a dimensáo pessoal, onde há que se desenvolver as relaçôes de envolvimento e os compromissos com a docência, bem como a compreensão das circunstâncias de realização do trabalho e dos fenômenos que afetam os envolvidos com a profissão e os mecanismos para se lidar com eles ao longo da carreira, a dimensáo organizacional, onde são estabelecidas as condições de viabilização do trabalho e os padrôes a serem atingidos na atuação profissional. (ALMEIDA; PIMENTA, 2011, p. 26)

Os elementos acima destacados constituem parte do ecossistema da formação docente, o que coloca o ensino em uma perspectiva de importância no contexto da universidade e da construção profissional. Os 
tempos que vivemos, de acelerado processo de modernização resultante da globalização e das mudanças nas formas de organização social, política e econômica sob o viés da lógica neoliberal, vem exigindo que acompanhemos o desenvolvimento tecnológico em nível mundial, em termos de qualidade, competitividade e produtividade. Nesse contexto, novos papéis se desenham no horizonte de todas as profissóes, e não seria diferente para a profissão docente, que é a base para as demais profissóes. No entanto, esse processo implica mudanças e elas não acontecem de um dia para outro, ainda mais quando tratamos de estruturas sociais e educacionais que se cristalizam através dos séculos, como é o caso da universidade. Com essa ideia colabora Morosini (2006, p. 48):

A partir da década de 1990, a universidade, uma das instituiçóes mais antigas do mundo e que perdura desde o período medieval, passa a sofrer fortes pressóes por mudanças, orquestradas por organismos internacionais. Rompem-se as fronteiras geopolíticas e instauram-se estratégias de mercado, nas políticas públicas, na gestão e na prática pedagógica universitária (tese da convergência).

Sob esse viés, as mudanças são necessárias e inevitáveis: refletir sobre a docência e a profissionalidade são parte inerente ao trabalho docente para quem deseja ser professor de nível superior, como já o é em todos os outros níveis de ensino.

Embora a profissão docente já tenha sido marcada por estereótipos diversos - desde considerar o professor aquele que sabe tudo, passando pela ideia de que não é profissão mas vocação, até ser visto como um sujeito desprendido, humilde -, professor é profissão que exige profissionalismo, antes de mais nada. O docente, como qualquer outro profissional, precisa capacitar-se para dar conta das relaçóes complexas do universo educacional. Exercer a docência torna-se, assim, um repto muito grande no atual universo educacional, pois se exige uma profissionalidade que inclui a abertura a desafios inovadores, à descoberta de novas metodologias, à cooperação com os pares, à habilitação para tratar de assuntos que envolvem os problemas cotidianos das profissôes. 
As exigências estabelecidas pelo Ministério da Educação e Cultura (MEC) nas Diretrizes Curriculares Nacionais (DCN) e seu impacto no Projeto Pedagógico de Curso (PPC) estabelecem ao docente uma participação e envolvimento muito maiores do que a ação de ensinar o que sabe a alunos que não sabem no espaço da sala de aula. Associa ensino com pesquisa, disposição para trabalhar com projetos de pesquisa e extensão e o trato de questôes inerentes à atuação do professor universitário. Masetto (2002) nos alerta que as competências necessárias ao professor universitário são fundamentais na construção de sua profissionalidade e devem superar a concepção de que essa tarefa seria apenas uma forma de complementar o tempo restante ao empregado em sua real profissão, seja a de engenheiro, advogado, médico etc. A competência em uma determinada área do conhecimento,

[...] significa, em primeiro lugar, um domínio dos conhecimentos básicos numa determinada área, bem como experiência profissional de campo, domínio este que se adquire, em geral, por meio dos cursos de bacharelado que se realizam nas universidades e/ou faculdades e de alguns anos de exercício profissional. (MASETTO, 1998, p. 19)

Aponta-se ainda para a competência na área pedagógica, sendo esse um dos principais problemas vivenciados pelos alunos em sala de aula. Como um profissional de uma profissão específica pode adquirir conhecimentos pedagógico-didáticos e o domínio da experiência na sala de aula se ele apenas aprendeu uma profissão determinada? Esse ponto apresenta-se, em geral, como o mais deficitário no processo de formação docente, seja porque o profissional entenda que quem sabe fazer sabe ensinar, considerando desnecessário refletir sobre as questóes de cunho pedagógico, seja porque não existe o reconhecimento sobre a importância do domínio da competência no campo pedagógico-didático. Ainda conforme Masetto (1998), não se pode falar de profissionais da educação se eles não dominam o processo de ensino-aprendizagem, se não sabem como conceber e gerir o currículo, como orientar as atividades de construçáo conjunta do conhecimento e do domínio das tecnologias da informação e da comunicação. 
Há também, dentre essas habilidades, a necessidade do exercício da dimensão política, que implica posicionamento e tomada de decisão, açôes a partir das quais o professor, ao atuar em seu ambiente de trabalho, o faz na totalidade do seu ser, destacando o compromisso e a responsabilidade social que cada um de nós tem enquanto cidadão. A dimensão política e cidadã da profissão docente precisa manifestar-se na atuação pedagógica, por meio de metodologias que conduzam os educandos a pensar reflexivamente sobre sua profissão e sua atuação cidadã no mundo. Ao entrar na universidade, ou na sala de aula, o professor

Tem uma visão de homem, de mundo, de sociedade, de cultura e de educação que dirige suas opções e suas açôes mais ou menos conscientemente. Ele é um cidadão, um "político", alguém comprometido com seu tempo, sua civilização e sua comunidade, e isso náo se desprega de sua pele no instante em que ele entra na sala de aula. (MASETTO, 1998, p. 23)

Diante do exposto, evidenciam-se as diversas nuances que envolvem a prática docente, o que deixa claro que a docência por si só é uma profissão que exige qualificação e não pode pautar- se no amadorismo. É preciso desenvolver competências e habilidades específicas, mas principalmente entender que a educação atual precisa se valer de uma reflexão que conduza à conscientização do diferencial que envolve a docência.

O docente da Educação Superior precisará estar preparado para trabalhar com a diversidade das pessoas que terá em sua sala de aula. Ele terá que ter capacidade de trabalhar com seres humanos, acima de qualquer outro objetivo. Os jovens e os adultos que chegam à Educação Superior trazem as marcas que a sociedade imprime neles, por vezes de violência, discriminação e exclusão. É nesse contexto que ele estará envolvido e se espera dele que possa dar conta da diversidade, das angústias, dos conhecimentos que preparam para os cada vez mais competitivos e exigentes mundos do trabalho.

A complexidade da profissão docente manifesta-se ainda maior se levarmos em conta as tantas formas de adquirir conhecimentos utilizadas pelos jovens no cotidiano. A tudo isso se soma a necessidade de compreender que o docente trabalha com sujeitos que têm uma história 
própria, que têm caráter individual, irrepetível e único. Saber lidar com essa diversidade de situaçóes faz toda a diferença no momento em que se está em uma sala de aula da universidade, em um colegiado de curso ou em um grupo de pesquisa.

A formação hoje, tanto do professor quanto do aluno, terá possivelmente que centrar-se na ótica da totalidade, partindo do pressuposto de que a Educação Superior tem a responsabilidade de formar seres humanos capacitados em uma profissão, mas também de forma-los para a cidadania. A formação profissional envolve, nesse sentido, competências para a ação no mundo, especialmente no mundo do trabalho. Como sujeito, o profissional é um cidadão que precisa dar conta de suas tarefas técnicas, mas também das relaçôes humanas estabelecidas no conjunto de sua profissão.

Percebe-se a necessidade de formaçáo específica para a docência, uma vez que ser professor não é apenas ensinar o desempenho de uma função técnica na sociedade, cabendo estimular o aluno ao processo constante de aprendizagem, em inúmeros sentidos, para que se possa dar conta, não apenas da profissão, mas das relaçóes em que está inserido. A dinâmica do mundo do trabalho vai exigir do aluno formado em um curso superior habilidades de mover-se em açóes que vão para além do conhecimento de uma profissão.

O que está se perdendo no contexto atual das relações é a capacidade de resolver pequenos problemas de convivência, de interrelação, de trabalho em equipe, de divisão de tarefas. Esse papel está implícito na função da universidade enquanto formadora de seres humanos solidários, críticos, reflexivos e responsáveis pela construção de uma sociedade minimamente acolhedora de todos. Esse papel não está mais sendo exercido pela comunidade familiar, em muitos casos, e nem mesmo pela sociedade. Sabe-se que a universidade não pode assumir todos os papeis sociais e de humanização, mas uma parcela deles cabe à Educação Superior, à universidade e aos seus docentes.

\section{Novas (?) exigências no processo de ensino-aprendizagem?}

Para que se cumpram as diferentes tarefas apontadas como exigência para a profissão docente, há que se realizar um processo de inovação na 
universidade. A palavra inovação comporta vários significados, por isso, trazemos aqui a concepção de Saviani (1989, p. 20-21) apontando para a concepção dialética do termo:

A concepção dialética aponta, pois, para um sentido radical de inovação, isto é, inovar significa mudar as raízes, as bases. Trata-se, pois, de uma concepção revolucionária de inovação. Pode-se ir, agora, mais além na explicitação do critério enunciado. Dizer-se que algo é inovador porque se opõe ao tradicional significa aqui não apenas substituir métodos convencionais por outros. Trata-se de reformular a própria finalidade da educação, isto é, colocá-la a serviço das forças emergentes da sociedade.

Inovar, no universo educacional, às vezes confunde-se com mudar métodos antigos, substituindo-os por novos e que produzem os mesmos efeitos. Tomando como base esse breve excerto de Saviani, compreendemos que inovar pressupóe reformular o sentido e a finalidade da educação, desenvolvendo o pensamento crítico e reflexivo que se manifesta na capacidade de questionar a realidade, problematizar e explicar os fenômenos. Esse exercício envolve a totalidade do sujeito, inclusive seus valores morais e sociais. Esse seria um aspecto inovador na educação atual. Outro aspecto importante a ser desenvolvido nos estudantes da Educação Superior é o trabalho colaborativo, com espaços para o trabalho em grupo e o debate. Assim, o estudante é chamado a autogerir-se, construir significados e monitorar seu próprio processo de aprendizagem, atuando o docente como orientador desse processo.

Percebe-se, assim, que é necessária a compreensão do processo educativo com foco no professor, nos estudantes e na aprendizagem, passando da transmissão de conteúdos para o aprender de forma autônoma e comprometida, gerando significados nas aprendizagens desenvolvidas. Nesse sentido, faz-se necessário desenvolver continuamente outras estratégias, métodos e técnicas pedagógicas. Para isso, algo importante é saber os fins a atingir. À universidade cabe instigar à investigação, ao trabalho em equipe e em colaboração, à exposição do conhecimento por parte de professores e alunos e à avaliação formativa. 
Essas estratégias são entendidas como capazes de desenvolver curiosidade, sentido crítico, colaboração, criatividade, sociabilidade, entre tantas outras competências. A inovação pedagógica exigirá muito mais dos professores, que terão que desenvolver sua profissionalidade enquanto se constroem professores, já que a legislação é omissa quanto à necessidade de formação para os professores que atuarão como docentes nas universidades. Não havendo exigências, certamente poucos deles tiveram a oportunidade de desenvolver essas competências, ou náo se interessaram por elas quando acadêmicos.

A inovação tem sido muitas vezes confundida com o uso das novas tecnologias de informação, contudo, inovar não é confrontar coisas novas às tradicionais, não é conceder toques requintados às técnicas e metodologias do passado. A inovação está na reformulação do próprio sentido da educação, na alteração das suas finalidades, formas e métodos - inovar é colocar a educação a serviço de novos objetivos. Mas isso não basta, pois atualmente se percebe, em determinadas políticas públicas, que a educação tem campo livre para estar a serviço do modelo de sociedade que se impóe, a capitalista, do lucro e do mercado. Nosso entendimento é de que educação não combina com mercadoria, por isso, acreditamos que urge inovar, no sentido de cumprir o objetivo e a tarefa de humanizar o humano pela educação. Isso, sim, poderia representar uma grande inovação no campo educacional.

\section{Consideraçóes finais}

A formação em programas stricto sensu que, segundo a LDB/96, podem habilitar para atuar como docente universitário nem sempre oferecem em seus currículos possibilidades de estudo, debate e reflexão sobre a construção de saberes didático-pedagógicos, ou o contato direto com a docência. Como destacamos, esses conhecimentos, geralmente, são vistos como saberes de segunda ordem, tendo relevância apenas os saberes específicos de determinada área de formação.

No entanto, como discorremos ao longo do texto, a docência universitária é uma atividade profissional complexa, que requer formação específica. Ao mesmo tempo em que se apresenta tal afirmativa surgem no- 
vos questionamentos, como o que nos faz Imbernón (p. 95, 2012): "Qual é a parte substantiva da profissão universitária? A pesquisa? A docência? A gestão? Tudo?” Se analisarmos esse conjunto, considerando as palavras do autor, é possível perceber a complexidade da profissão docente na universidade.

Advogamos a ideia de que, além dos conhecimentos específicos, o professor universitário precisa desenvolver a capacidade de se comunicar e de se fazer entender, desenvolver aulas em conjunto com os seus alunos, propiciar um ambiente de ativa participação e intercâmbio. Para tanto, precisa ter domínio dos conteúdos da sua disciplina, um bom relacionamento com suas turmas e, sobretudo, saberes didático-pedagógicos que possibilitem pensar novas metodologias que ajudem os alunos a darem sentido ao conhecimento.

Mediante o exposto, no que se refere aos saberes que constituem a formação do docente universitário, vale destacar a importância da formaçáo continuada com vistas ao desenvolvimento de aulas atualizadas e com metodologias inovadoras que propiciem aos alunos a aprendizagem e a construção crítica de conhecimentos. Dessa forma a universidade cumprirá com sua função social e seu papel na formação cidadá.

O papel do docente universitário sempre foi desafiador e cada vez que exigem novos posicionamentos, conhecimentos, formação e reflexóes para que o ensino e a aprendizagem sejam de qualidade. Uma formação que contemple diferentes saberes, sem dúvida, propiciará aos professores universitários suporte metodológico, fundamentação teórica e alternativas práticas para a melhoria da qualidade da docência universitária.

A profissão professor exige flexibilidade no enfrentamento à imprevisibilidade contemporânea, assim como para a construção de um pensar e agir compartilhado diante das incertezas e dificuldades. A pesquisa, como maneira concreta de ação inovadora, proporciona a descoberta, a invençáo e a criaçáo. Diante dos desafios sempre novos da profissão docente o professor universitário deve profissionalizar-se para desenvolver com qualidade o fazer pedagógico, o conhecimento específico de sua área, o saber interdisciplinar e abrangente de sua realidade social e a de seus alunos, além de construir-se como cidadáo ativo na sociedade. Eis os desafios. 


\section{Notas}

1 A internacionalização vem surgindo, ao lado da extensão, da pesquisa e do ensino, como mais um pilar da universidade, segundo autores como Santos e Almeida Filho (2012).

2 Presidida pela racionalidade técnica, contempla apenas duas formas de conhecimento disciplinar: as disciplinas formais da lógica e da matemática e as ciências empíricas segundo o modelo mecanicista de ciências naturais. (SANTOS, 1988)

3 Tomamos como referência, estudo desenvolvido por Pimenta e Almeida (2011), na USP em que demonstram a preocupação com o ensino nos cursos de graduaçấo e apresentam estudos de como tem sido discutida essa questão na universidade.

\section{Referências}

ALMEIDA, Maria Isabel de e PIMENTA, Selma Garrido. A construção da docência universitária no âmbito da Universidade de São Paulo. PIMENTA, S.G. e ALMEIDA, M. I. (org.). In.: Pedagogia universitária: caminhos para a formação de professores. São Paulo: Cortez, 2011.

CERUTTI, Elisabete e NOGARO, Arnaldo. Desafios docentes no ensino superior: entre a intencionalidade pedagógica e a inserção da tecnologia. In.: RIAEE - Revista Ibero-Americana de Estudos em Educação, v.12, n.3, p. 1592-1609, jul./set. 2017.

CUNHA, Maria Isabel da. O bom professor e sua prática. 10. ed. Campinas, SP: Papirus, 2000.

CUNHA, Maria Isabel da. Políticas e docência na universidade: novas configurações e possíveis alternativas. In.: CUNHA, Maria Isabel da (Org.). Formatos avaliativos e concepçôes de docência. Campinas, SP: Autores Associados, 2005.

CUNHA, Maria Isabel da Inovaçóes pedagógicas: o desafio da reconfiguração de saberes na docência universitária. Cadernos Pedagogia Universitária. São Paulo: USP, 2008.

CUNHA, Maria Isabel da A docência como atividade complexa. In: CUNHA, Maria Isabel da. Trajetórias e lugares de formação da docência universitária: da perspectiva individual ao espaço institucional. Brasília, DF: CAPES; CNPq, 2010.

FÁVERO, Altair Alberto. A formação de docentes universitários no contexto da expansão da Educação Superior. In: XI Congresso Nacional de Educação - EDUCERE, 2013, Curitiba - PR. Anais do XI Congresso Nacional de Educação - EDUCERE. Curitiba - PR: PUCPR, 2013. p. 7876-7887.

FREIRE, Paulo. A educaçâo na cidade. Rio de Janeiro: Paz e Terra, 1991.

FREIRE, Paulo. A educação na cidade. 2. ed São Paulo: Cortez, 1995. 
GARCIA, Marcelo C. Formação de professores: para uma mudança educativa. Portugal: Porto Editora, 1999.

IMBERNÓN, Francisco. Inovar o ensino e a aprendizagem na Universidade. São Paulo: Cortez, 2012.

LEITE, Carlinda e RAMOS, Kátia. Questóes da formação pedagógica-didática na sua relação com a profissionalidade docente. In.: LEITE, Carlinda (org.). Sentidos da Pedagogia no ensino superior. Porto, Portugal: Legis Editora - CIIE/Livpsic, 2010.

LUCARELLI, Elisa. Paradojas de um rol: el assessor pedagógico em la univesidad. In: LUCARELLI, E (Org.). El assessor pedagógico em la universidad: de la teoria pedagógica a la práctica em la formación. Buenos Aires: Paidós, 2004.

MASETTO, Marcos T. Competência Pedagógica do professor universitário. São Paulo: Summus, 2003.

MASETTO, Marcos (Org) Docência na Universidade. 4 ed. Campinas: Papirus, 2002.

MASETTO, Marcos T. Professor Universitário: um profissional da educação na atividade docente. In: MASETTO, Marcos T. (org.). Docência na universidade. Campinas, SP: Papirus, 1998. p. 9-26.

MOROSINI, Marília. Docência na educação superior. In.: Coleção Educação Superior em Debate. v. 5. Brasília, 1o e 2 de dezembro de 2005 / Organização: Dilvo Ristoff e Palmira Sevegnani. - Brasília: Instituto Nacional de Estudos e Pesquisas Educacionais 
SANTOS, Fernando Seabra; ALMEIDA FILHO, Naomar de. A quarta missão da Universidade: internacionalização universitária na sociedade do conhecimento. Brasília: Editora Universidade de Brasília; Coimbra: Imprensa da Universidade de Coimbra, 2012. 238 p.

TARDIF, Maurice. Saberes Docentes e Formação profissional. Petrópolis, RJ: Vozes, 2002.

Presidida pela racionalidade técnica, contempla apenas duas formas de conhecimento disciplinar: as disciplinas formais da lógica e da matemática e as ciências empíricas segundo o modelo mecanicista de ciências naturais. (SANTOS, 1988)

Recebido em 2I dez. 2017 / Aprovado em 20 jan. 2019

Para referenciar este texto:

CANAN, S. R.; SANTOS, C. F. S. Educação superior em tempos de crise: há espaço nas políticas de educação para a discussão do professor universitário? EccoS - Revista Cientifica, São Paulo, n. 48, p. 339-36r. jan./mar. 2019. Disponível em: <https://doi. org/I0.5585/EccoS.n $48.8201>$. 
